\title{
LA PALMA AFRICANA EN EL PACÍFICO COLOMBIANO: SU ILEGALIDAD, CONSECUENCIAS Y VIOLACIÓN DE DERECHOS TERRITORIALES
}

\section{Nixon Arboleda Montaño}

Afrocolombiano oriundo de Guapi, pacífico caucano y estudiante de Administración del Medio Ambiente de la Universidad Tecnológica de Pereira

nixon@utp.edu.co

Manizales, 2008-12-04 (Rev. 2008-11-14)

\section{RESUMEN}

La gran biodiversidad presente en el pacífico colombiano ha sido y está siendo devastada por la agroindustria de la palma africana (revitalizada con el auge de los agrocombustibles); de igual forma se han presentado graves problemas de pérdida y violación de derechos sobre el territorio (protegido por la ley 70 de 1993 y la constitución de 1991), desplazamiento y cambio en las condiciones de vida de la comunidad local (en su mayoría afrocolombiana); y se ha negado la posibilidad de gestar su propio desarrollo a los pobladores del litoral pacífico.

\section{PALABRAS CLAVES}

Agrocombustible, biodiversidad, comunidades afrocolombianas, impacto, ley 70 , pacífico colombiano, palma africana, territorio colectivo.

\section{AFRICAN OIL PALM IN THE COLOMBIAN PACIFIC COAST: ITS ILLEGALITY, CONSEQUENCES AND VIOLATION OF TERRITORIAL RIGHTS}

\section{ABSTRACT}

The great biodiversity present in the Colombian Pacific Coast has been and is being devastated by the agroindustry of African palm (revitalized by the biofuels boom). Additionally, severe problems regarding the violation of territorial rights (protected by Law 70 of 1993 and the 1991 Political Constitution) have arisen, as well as displacement and changes in the life conditions of the local community (mostly AfroColombian). This Pacific Coast community has been denied the possibility of creating their own development.

\section{KEY WORDS}

Biofuels, biodiversity, Afro-Colombian communities, impact, Law 70, Colombian Pacific Coast, African oil palm, collective territory.

\section{INTRODUCCIÓN}


Infortunadamente estamos en un país que pareciera no importarle las diferencias y, por ende, las diversas lógicas de comprender el mundo. Se podría decir que, además, la lógica capitalista no tiene en cuenta esas divergencias; es así como desde ese razonamiento, a los pobladores del pacífico no se les ha dado la oportunidad de forjar su propio "desarrollo". De esta forma, desde el centro del país se ha decidido lo que le conviene o no a esta región, decisiones que se han materializado en planes, programas y proyectos que lo único que han logrado es agravar la situación ambiental y social del pacífico colombiano. Dentro de este enfoque nefasto hace ya más de dos décadas se presenta la amenaza de la palma africana, peligro que hoy en día -con la explosión de los agrocombustibles- se ve más agudizado. La biodiversidad también ha sido víctima de este modelo y seguirá siéndolo mucho más con las modificaciones genéticas que se le están haciendo a la palma.

\section{CONTENIDO}

\subsection{La biodiversidad del Pacífico juna razón para no deforestar!}

El concepto "biodiversidad" se ha definido de diferentes maneras, pero, en general, el significado de diversos autores llega a la misma conclusión: biodiversidad es la variabilidad de organismos vivos de cualquier fuente, incluidos además los ecosistemas; comprende la diversidad dentro de cada especie, entre las especies y de los ecosistemas. La biodiversidad incluye también las diferentes culturas y etnias que viven en un territorio, igualmente se hace necesario resaltar la fauna y flora que el ser humano ha domesticado.

Si medimos la biodiversidad por kilometro cuadrado encontramos que a nivel mundial Colombia es el país más biodiverso; no obstante, esta inmensa riqueza biológica que tiene el país no está distribuida homogéneamente.

Dentro de la diferenciación anterior se puede decir que el pacífico Colombiano (también se le conoce como el Chocó Biogeográfico) es la región que alberga la mayor riqueza de nuestro territorio. Infortunadamente este potencial con que cuenta nuestra nación, y en especial la región en mención, sólo es cuestión de retórica ya que en la práctica se hace muy poco para protegerla y aprovecharla sustentablemente.

Por mencionar sólo dos ejemplos, citamos que "en el pacifico colombiano se encuentran entre siete y ocho mil especies de plantas (de las 45.000 que puede haber en Colombia), en el mismo sentido rescatamos que en el Parque Nacional Natural Los Katios se sobrepasa las 600 especies de aves; es decir, más de las existentes en toda Norteamérica" (Germán, 1993). Adicional a la diversidad biológica con que cuenta el pacifico, se presenta la riqueza de metales preciosos, recursos que han sido y son explotados por foráneos y nacionales ajenos a la región.

Pese a la fragilidad de los ecosistemas del Choco Biogeográfico ${ }^{1}$ y gracias a los gobiernos y a políticas fallidas, esta región ha sido y es considerada como una despensa de recursos naturales" ${ }^{2}$ es así, "como para 1993 el 60\% de la madera consumida en el país procedía de esta región. Además aportaba con el $82 \%$ del platino, el $18 \%$ de oro y el $14 \%$ de plata; de igual forma la tala de bosques alcanzaba 100.000 hectáreas por año. En ese entonces se calculaba que a ese ritmo, en menos de 50 años la selva del pacífico habrá desaparecido" (Servio, 1993). Desde luego que la mayoría (por no decir toda) de la madera que se tala en 
el pacifico se extrae de la selva (bosques naturales) y la explotación de los recursos mineros es realizada por empresas extranjeras y nacionales que dejan pocos dividendos en la región, a causa de generar grandes impactos ambientales y sociales negativos.

Otro agravante frente a la biodiversidad del territorio en estudio es insignificante investigación frente a lo que hay por descubrir ${ }^{4}$, lo que en palabras de Alwyn Gentry se traduciría en decir "que sabemos más de la luna que del pacifico colombiano".

Inspirado en Gentry y dado el panorama anterior, sería muy útil preguntarse ¿cuál, entonces, será la suerte de la biodiversidad del Choco biogeográfico? Ya sabemos que no sabemos casi nada sobre ella, que tiene valores ecológicos, estéticos sociales y económicos, y que está desapareciendo.

También es válido decir que no sólo en el Litoral colombiano se está viendo amenazada su biodiversidad, por el contrario, se hace importante resaltar que la expansión que en las últimas décadas ha presentado la palma africana (revitalizada con el auge de los agrocombustibles) también se está llevando a cabo en otros países $^{6}$ que albergan gran cantidad de la selva húmeda tropical $\mathrm{y}$, como sabemos, esto se hace a costa de deforestar millones de áreas de estas selvas, además de cultivos que sirven de sustento y ofrecen alimentos a las comunidades locales.

Dado el panorama mundial, surge la necesidad de plantear que antes de diezmar la biodiversidad de la región pacífica con iniciativas (que llegan desde afuera) como la palma africana, deben fomentarse y/o construirse iniciativas que le apunten a un verdadero "desarrollo" (etnodesarrollo) de este territorio tan golpeado. Con la riqueza natural y cultural presente en la región pacífica los pobladores locales puede desarrollar alternativas que conduzcan a mejorar sus condiciones de vida, ejemplos claros son el caso del borojó y el chontaduro (antes frutos desconocidos) que pueden ser transformados en diferentes productos que gracias al hecho de ser considerados como "afrodisiacos" pueden presentar alta demanda en el mercado doméstico e internacional.

La modificación genética de la palma africana es otro problema al que se enfrenta la biodiversidad del pacífico, ya que ahora está expuesta al gran peligro de ser modificada a través de la dispersión de semillas o por la acción de las aves. Teniendo en cuenta que posiblemente no todo el aceite generado por la palma africana va a ser destinado para producir agrocombustible, se hace necesario alertar sobre los efectos a la salud humana de estos productos manipulados genéticamente, ya que podrían ser graves. Los impactos sobre el ambiente podrían ser irreversibles. $Y$ todo este proceso sólo tendrá una razón: generar beneficios para la industria y el comercio.

Con todo lo anterior "se abre así la oportunidad de desarrollar un nuevo modelo, un nuevo esquema netamente tropical que reivindique y aproveche la biodiversidad, en vez de reducirlo todo a la monocultura y la uniformidad" (Gentry, 1993). De esta forma vemos que una plantación como la palma africana (ligada a intereses privados y ajenos a la comunidad) atenta contra la biodiversidad (al ser causante de deforestación y cambiar los usos de la tierra) y, por ende, contra las oportunidades de las poblaciones del pacífico colombiano y comunidades locales en el resto de Colombia y el mundo. 


\subsection{La palma africana y sus consecuencias socioambientales en el Chocó biogeográfico}

La palma africana (o aceitera) "es una planta originaria de la zona intertropical húmeda de África" (Sokoudjou, 2001) que gracias al "boom" de los agrocombustibles hoy en día se está esparciendo por muchas zonas del mundo. De esta plantación puede decirse "que, al igual que en caso de los cultivos forestales de pinos y eucaliptos, el problema no es el árbol, sino el modelo en el que se lo implanta" (Carrare, 2001); también podría argumentarse que el dilema no es la palma, el meollo del asunto está en preguntarse ¿al servicio de quién está?

Donde quiera que se pretenda plantar la palma aceitera se arguye generación de empleo y beneficios al ambiente, hasta se dice que con ésta también llega el "desarrollo". Estos argumentos se contradicen en la práctica, ya que la capacidad generadora de empleo de esta actividad es muy baja y los empleos generados son de muy mala calidad en todos los sentidos ${ }^{7}$, además; uno de los principales impactos de la palma es la apropiación de amplias áreas de tierra que antes pertenecían a las poblaciones locales (en no pocos casos suscitando problemas de tenencia de la tierra y desplazando forzado).

"En el mismo sentido se puede decir que el auge en las plantaciones de palma sirve a los intereses de las elites locales y de las empresas transnacionales con las que se alían para la obtención de beneficios mutuos, y más grave aún es la globalización que ha venido experimentando la palma aceitera, hecho que conduce a que las grandes empresas (crecientemente extranjeras) se lleven todos los beneficios al controlar la producción, la industrialización y la comercialización en todos los niveles" ( Sokoudjou, 2001).

Así las cosas, "la agricultura pasó de apoyarse en un flujo de energía renovable para transformarse en un actividad muy exigente en combustibles fósiles y recursos no renovables" (Pérez - Rincón, 2008). Es de esta forma como la palma aceitera utiliza fertilizantes (que se hacen con derivados del petróleo), además en su proceso industrial para generar aceite y posteriormente biodiesel se requiere de combustibles fósiles; en fin, lo que se plantea es que en el caso de este agrocombustible y otros, el balance energético no los favorece, ya que por cada unidad de energía gastada en energía fósil, el retorno en agrocombustible ("biodiesel" o "bioetanol") es menor a esa cantidad, lo que en términos más palpables lleva a decir que es más lo que se invierte en energía fósil para producir agrocombustibles, que la energía que estos generan; obviamente el sector que los promueve arguye que el balance es a favor de los agrocombustibles.

Desde el concepto de desarrollo sostenible ${ }^{8}$, teniendo en cuenta sus tres pilares, a saber: el ser humano (sostenibilidad social), el planeta (sostenibilidad ambiental) y los beneficios (sostenibilidad económica) (Vargas, 2007). Se puede considerar que la agroindustria de la palma africana no sólo en Colombia, sino a nivel mundial, se ha caracterizado por no realizar una producción sostenible debido a que sólo ha alcanzado la sostenibilidad económica. De esta forma nos adentramos al litoral pacífico.

Ahora bien, en la incursión de la palma africana en el pacifico colombiano ${ }^{9}$ se arribó al "pueblo atrasado de Tumaco 'costa pacífica nariñense', donde para finales de los 50's, el gobierno se encontraba iniciando la primera granja experimental, la cual habría de convertirse en punto de apoyo para el lanzamiento en grande del cultivo de palma en la región a partir de 1980" (Escobar y Pedrosa, 1996). 
Desde ese entonces ya se podría prever que esta plantación no se implementaba con las mejores intensiones del caso, es decir, no buscaba generar bienestar para las poblaciones locales. Es así como un experto de la FAO que acompaño este proceso argumentaba que "los agricultores de los grandes medios financieros debían instalarse en las condiciones más recomendables, sobre terrenos planos o simplemente ondulados y se debían esforzar para que cada uno hiciera un mínimo de 1.000 hectáreas" (Ferrand, 1996).

Así mismo, "hacia la primera mitad de los 80's en este municipio ya existían ocho empresas de la reina de las oleaginosas (palma africana) y en 1996 Colombia $^{10}$ ocupaba el quinto puesto a nivel mundial como productor de aceite de palma, después de Malasia, Indonesia, Nigeria y Costa de Marfil" (Escobar y Pedrosa, op. cit.)

Las consecuencias de las plantaciones de palma no se hicieron esperar, es así como para mediados de los años noventa en Tumaco ya existía una reconfiguración del territorio. De esta forma Escobar (1996) plantea que:

"La plantación ha inventado un nuevo modelo de posesión de la tierra, del trabajo y del dinero. El progreso de la misma, en otras palabras, se ha logrado a costa del devenir del bosque, de los ríos (ahora seriamente contaminados por los desechos agrícolas e industriales de la plantación), de la producción local para la subsistencia, y, lo más importante, al precio y el devenir de la mujer y el hombre afro, de su cultura (...) La disciplina se impone, reemplazando la diversidad" (Escobar y Pedrosa, op. cit.).

Para el año 2000 , la palma ya cubría casi la mitad de la superficie $(47.6 \%)$ del municipio nariñense (Tumaco), tierra que hasta hace tres o cuatro décadas estuvo predominantemente cubierto por pequeñas fincas o extensiones de bosques (...) esta expansión de la palma ha significado múltiples cambios en la vida de las gentes. De un lado, se ha producido un desplazamiento poblacional forzado, articulado al avance de las plantaciones debido a que éstas compraron (muchas veces a la fuerza) o se tomaron las tierras más fértiles donde habitaban cientos de pequeños propietarios (Restrepo, 2004).

Las modalidades de plantar la palma son básicamente dos. Una primera modalidad es la agroindustrial, practicada por las grandes y medianas empresas. Una segunda es la local $^{11}$, que es desarrollada por los nativos que aún conservan pequeñas parcelas. En la primera, la rentabilidad del capital es la lógica a la que explícitamente se le juega y, en la segunda, los afrocolombianos que no fueron desplazados por la expansión y consolidación de los cultivos industriales, contribuyen con su producción a alimentar las plantas extractoras de la zona. La última modalidad tiene que ver mucho con el mercado local, en el cual los afrocolombianos participan de diferentes formas: ofrecen su producto a una planta extractora (al mismo al precio que localmente se paga por tonelada); el endeude, y la opción de los intermediarios (a un precio menor que el de la planta) (Restrepo, op. cit.).

Esta forma de mercado garantiza que los precios pagados por las empresas no sean justos y los manejen a sus amaños, de lo que se deriva que realmente esta plantación no representa mejores ingresos para las poblaciones locales y, mucho menos, representa mejoramiento en la calidad de vida, sin mencionar los impactos ambientales que se generan como consecuencia de esta agroindustria ${ }^{12}$. 
También cabe destacar que este modelo es agresivo hasta con la gente que emplean, debido a que las condiciones de trabajo son paupérrimas y no hay garantía de estabilidad laboral, lo que se ve representado en el hecho de que "la gente trabaja a destajo (se le paga por la productividad de la persona) o por jornal, así que el número de empleados permanentes que cuenta con un salario mínimo y seguridad social es pequeño" (Escobar y Pedrosa, op. cit.).

Estudios como los del Instituto Alexander Von Humboldt demuestran contundentemente los impactos negativos de la palma aceitera en Tumaco al establecer que en este municipio hay una pérdida de entre 22 y un $40 \%$ de las especies de mamíferos (Diócesis de Quibdó, 2004).

Las consecuencias desastrosas suscitadas por el modelo bajo el cual se implanta la palma se esparcen luego por otros departamentos que tienen jurisdicción en el Litoral pacífico, hecho que se presenta básicamente por unas condiciones favorables. Es de esta forma, como por las condiciones bioclimáticas, de aislamiento, inexistencia de protección ambiental y protección de la fuerza legal (ejercito) y al margen de la ley (paramilitares), que la palma africana se ha seguido propagando en la región en cuestión, esta vez en el departamento del Chocó, ocasionando graves impactos ambientales (perjudicando así, las tres principales riquezas de la región: la biodiversidad, el agua y los bosques) y, lo que es peor, generando violencia, suceso que conllevó a cambiar la vida de las muchas personas.

De esta forma a "las comunidades afrodescendientes de Juguamiandó y Curvaradó la violencia militar y paramilitar las forzó a dejar sus tierras, que fueron ilegalmente ocupadas por la empresa Urapalma en el año 2001" (Vargas, 2008).

Este caso entonces,

"resulta ilustrativo de las formas bajo las cuales se implementa esta estrategia de exterminio de las comunidades negras del pacífico colombiano (...) evidenciándose en el informe que para el año 2005 hace público el Incoder, certificando que el 93\% de las áreas sembradas por cultivos de palma pertenecientes a las empresas Urapalma, Palma de Curvaradó, Palmas S.A. y Palmadó, se encuentran en territorios colectivos; señala que al tiempo se constata que casi la totalidad de los caseríos tradicionales han desaparecido y hay proceso de repoblamiento con personas distintas a las comunidades desplazadas"

Si con la reglamentación de la ley 70 de 1993 pasa lo que pasa, cabría preguntarse entonces ¿cómo habrá sido la usurpación de las tierras en los años siguientes a la reglamentación de la ley, y peor aún, en los años anteriores a ésta?, la respuesta es muy clara: necesariamente debe haber sido peor. En el caso de Tumaco, municipio en el que la implementación de la palma aceitera se multiplicó a principio de la década de los años ochenta -época en que a los territorios colectivos de las comunidades negras se les llamaba tierras baldías ${ }^{14}$-, a la ocupación de las tierras declaradas como baldíos de la nación le siguió la compra de tierras (por palmicultores y obviamente se hizo por las buenas y por las malas) y últimamente (después de la expedición de la ley 70 de 1993) la invasión de territorios colectivos. Es de esta forma como los desplazados, por el avance de la palma, acabaron en el área urbana de Tumaco (Diócesis de Quibdó, op. cit.).

A manera de epílogo, se puede decir (no siendo pesimista) que son más bien pocas las ventajas y beneficios que se pudieron haber derivado con la llegada de la 
palma aceitera a la región pacífica y que, por el contrario, lo que se ha hecho es degradar un ecosistema (que de por sí es frágil) y afectar las condiciones de vida de una comunidad que quiere gestar su propio desarrollo. En esta misma línea se torna muy preocupante el hecho de que hoy en día empresas privadas apoyadas por el gobierno central están intentando negociar (dentro de una supuesta legalidad) en otras zonas de la región (caso del pacífico caucano) para implementar la palma en territorios colectivos de comunidades negras bajo el paradigma, que es bien sabido, de "generación de empleo y desarrollo".

\subsection{Los agrocombustibles como motor para la expansión de la palma africana}

En este inicio del siglo XXI estamos viviendo un gran debate sobre el tema energético; tema que traspasa todas las fronteras y que es motivo de discusión además- en campañas electorales, como es el caso del país más poderoso del mundo (Estados Unidos de Norte América). Este hecho se presenta como consecuencia del agotamiento del oro negro (petróleo), el gas y el carbón; como también -se arguye- por la crisis ambiental planetaria que estamos viviendo. Todo esto ha llevado a buscar fuentes de energías alternativas a estos recursos. Las fuentes de energías que se consideran más "promisorias son las obtenidas de los 'biocombustibles', la hidroenergia y la hidroelectricidad o, incluso, la energía nuclear"15(Vélez y Vélez, 2008). Otras fuentes que pueden llegar a jugar un papel protagónico son la solar, oceánica, eólica y los residuos sólidos; no descartando la geoenergía (inclusive se habla de generar energía a partir de trabajos con bacterias).

De todas esas fuentes de energía el tema que aquí nos ocupa son los "biocombustibles", que por cierto son muy controvertidos. Algunos plantean que el prefijo "bio", quiere decir que respeta la vida, pero que por los impactos que causan (ejemplo palma africana) no son tan amigables con el ambiente y, por ende, no debería llamarse así (Guhl, 2007). Otros consideran que "los biocombustibles son cualquier tipo de combustible líquido, sólido o gaseoso, proveniente de la biomasa (materia orgánica de origen vegetal o animal). Este término incluye alcohol etílico o etanol, metanol, biodiesel, diesel fabricado mediante el proceso químico de Fischer-Tropsch y combustibles gaseosos tales como hidrogeno y metano" (Arias, 2007).

Al respecto, consideramos más apropiado el concepto de agrocombustibles, que son considerados como "cualquier tipo de combustible líquido, sólido o gaseoso, proveniente de la biomasa vegetal, este término incluye principalmente dos tipos de combustibles: el 'Bioetanol' (o alcohol carburante) y el 'Biodiesel' " (Pérez - Rincón, 2008). Son de importancia el 'biodiesel' y el 'bioetanol' porque son combustibles líquidos que pueden ser generados a partir de plantaciones como la palma africana, caña, soya, maíz, entre otros. Obviamente cada plantación y/o cultivo sirven para producir un tipo de agrocombustible, como es el caso del fruto de la palma que puede ser destinado para producir 'biodiesel', o la caña a través de la cual se puede elaborar 'bioetanol'. Dado lo anterior, se puede precisar que el auge presente es frente a los agrocombustibles líquidos producidos a partir de biomasa.

El Bioetanol, o alcohol carburante, se define como compuesto orgánico líquido, de naturaleza diferente a los hidrocarburos derivados del petróleo, gas natural o carbón, que tiene en su molécula un grupo hidroxilo $(\mathrm{OH})$ enlazado a un átomo de carbono. El bioetanol se obtiene a través de un proceso de fermentación y destilación de plantas ricas en azúcar (caña de azúcar, remolacha), cereales (maíz, cebada) o madera (biocarburantes de segunda generación). Este sustituye la 
gasolina. Por su parte, el Biodiesel es un combustible para motores diesel, que se obtiene con un proceso llamado transesterificación a partir de semillas oleaginosas (palma aceitera, colza, girasol, soya, etc.). Substituye el diesel o el llamado ACPM en Colombia (lbíd., 88).

Realmente, el bioetanol y el biodiesel deberían tener nombres más específicos por la fuente que los genera (a partir de agrocombustibles), los cuales podrían ser agroetanol y agrodiesel.

Frente a los agrocombustibles -y con razón- se argumenta que han generado una agroindustria, la cual "hereda, reproduce y actualiza los viejos esquemas coloniales de tenencia de la tierra y expropiación de la fuerza del trabajo, así como el enclave europeo y norteamericano en los países del Sur" (Vélez, y Vélez, op. cit.).

El fruto de la palma africana es y ha sido utilizado para producir aceite y derivados, no obstante, con el "boom" de los agrocombustibles como fuente de energía, se ha prolongado el proceso químico-industrial y a partir de este fruto ya es posible obtener agrodiesel. Aunque el país también le ha apostado a esta política mundial, probablemente en la actualidad no se genera (o en pocas cantidades) agrodiesel a diferencia del agroetanol; sin embargo, existe toda una estrategia de implementar el sistema industrial (en las regiones claves) para empezar a producir este tipo de agrocombustible.

Después de cinco décadas de actividad, la palma aceitera en el país es un cultivo en consolidación, ocupando un territorio de 301 mil hectáreas en $2006^{16}$, con un crecimiento sostenido en los últimos diez años, tanto en el área sembrada $(8,5 \%$ promedio anual) como en la producción de aceite (5.9\%). Sin embargo, aún se está muy lejos de Malasia e Indonesia, los mayores productores, con un total de 4,2 millones y 5,2 millones de hectáreas de palma sembradas y una producción de 15,9 millones y 15,8 millones de toneladas, respectivamente (Pérez - Rincón, op. cit.).

En Colombia los departamentos con mayor presencia de plantaciones de palma africana corresponden a Nariño, Meta, Casanare, Santander, Cesar y Magdalena. Estos concentran el $94 \%$ del área sembrada del país. Aunque en poca cantidad (3.245 hectáreas) el departamento del Chocó también aporta a las cifras de la palma en el país y de esta forma junto a Nariño (28.000 hectáreas) se convierten en los representantes del pacífico respecto a la reina de las oleaginosas (ibíd., p. 88). Tampoco se puede dejar de decir que seguramente con las tendencias que se tienen, el número de hectáreas sembradas en palma ya aumentó en el Litoral pacífico y el resto del país y, lo que es peor, seguirá aumentando y no en la dirección que debería hacerlo, como se corrobora a continuación.

Por su parte Cenipalma y Corpoica plantean que el potencial de expansión del cultivo, según criterios edafoclimáticos, es de 3,5 millones de hectáreas, encontrándose el área potencial en los mismos departamentos: Nariño, Meta, Casanare, Santander, Cesar y Magdalena, sumándole también: Antioquia, Bolívar, Córdoba, La Guajira y el Norte de Santander. Sin embargo, acorde a otros planes de expansión que ya comienzan a tener desarrollos específicos, existen otras áreas de interés para los palmicultores como son: la Costa Pacífica del departamento de Nariño (agregándole la Costa Pacifica Caucana), Caquetá, Putumayo, Chocó, Guaviare y Vichada. Estos planes buscan reducir el grado de dispersión de los cultivos que incrementan los costos de producción (ibíd., p. 88). Aunque las condiciones climáticas pueden favorecer el establecimiento de la palma en la 
región pacífica, la consideración del pacífico como reserva forestal (mapas del IGAC, ley 99 de $1993^{17}$ ) demuestra que es necesario proteger la selva de esta región.

Otra gran crítica que se le hace a la palma africana es que a diferencia de sus principales competidores (colza, girasol, soya, etc.) es una plantación perenne, lo que implica el otorgamiento de derechos permanentes a los palmicultores (en el territorio donde se logre plantar la palma), en perjuicio de la población local. También se arguye que después de tantos años (una vez establecidas puede demorar hasta 50 años), con las tierras drenadas y fumigadas, es difícil que se recupere el bosque o se cambie la palma por otros cultivos. Es así como se torna supremamente complicado deshacerse de la palma una vez se haya establecido. Ahí sí, "como dijo un indígena malayo Nayak: las madereras destruyen nuestra selva y se van. Las compañías plantadoras destruyen nuestra selva iy se quedan!" (Movimiento mundial por los bosques tropicales, 2001).

\subsection{Territorio, legislación, palma aceitera y comunidades afrocolombianas}

Después de una profunda discriminación y exclusión de la sociedad a los afrocolombianos, se empiezan a presentar, a principios de la década del 90, algunos avances respecto a los derechos de estas comunidades, y la comunidad indígena. De esta forma la Constitución Política de 1991, en su artículo 63 y la ley 70 de 1993, reconoce que las tierras de los territorios colectivos de las comunidades negras, al igual que los resguardos indígenas, son inalienables, imprescriptibles e inembargables. Declaración que en teoría debería obstaculizar las inversiones de las trasnacionales en los territorios de estas comunidades (como es el caso de la región pacífica), que además albergan gran parte de la bioversidad del país y del mundo.

El artículo transitorio 55 de la Constitución Política de 1991 (en concreto fue de lo poco que se hizo a favor de las comunidades negras) dio origen a la ley 70 de 1993, ley que de por sí tiene vacios; no obstante, para este caso, lo importante es que dentro de sus bondades defiende el territorio rural de las comunidades afrocolombianas del Litoral pacífico, aunque por la fecha de expedición de la misma se hace evidente que antes no existía una figura que protegiera el territorio de estas comunidades, además, esta protección en la práctica ha sido más bien poco efectiva.

Lo otro que podría decirse es que esta ley tiene como objetivo entre otros (art 1) garantizar las prácticas tradicionales de producción, el derecho a la propiedad colectiva y la protección de la identidad cultural. Derechos que se violan y vulneran con el establecimiento de la palma africana en los territorios colectivos de las comunidades afrocolombianas, porque la misma acaba con dichas prácticas tradicionales al obligar a las poblaciones a cambiar sus cultivos y tener que dedicarse a otras actividades (siembra y manejo de la palma); esto conlleva a la perdida de la identidad cultural debido a que tal identidad está en gran parte asociada a la forma de producir. Además, la propiedad colectiva se ve amenazada ya que los palmicultores buscan comprar estas tierras o hacer convenios que en la práctica le apuntan al desmedro y pérdida de propiedad del territorio. También es importante reconocer que:

"Los monocultivos de palma, por su extensión (grande para ser rentable) (...) sus requerimientos agroecológicos (el exceso de agua mata a la palma por lo que hay que drenar los terrenos), su necesidad de insumos (herbicidas, plaguicidas, 
fertilizantes), su necesidad de mano de obra intensiva y eficiente (lo que obliga a duras condiciones laborales), su necesidad de que haya alguna planta extractora de aceite (lo cual contamina el aire y el agua, con sus emisiones y vertimientos respectivamente) $y$, sobre todo, la sustitución de bosques originales hacen incompatibles las plantaciones de palma con la función ecológica y social determinada para los territorios colectivos de comunidades afros y indígenas $\$ 18$ (Diócesis de Quibdó, op. cit.).

Los territorios colectivos están blindados contra la palma y cualquier otra imposición que llegue desde afuera.

"Es así como en el artículo 7 de la ley 70 se establecen los términos de la garantía que se les da a las comunidades afrocolombianas del pacífico, para que no pierdan su territorio, como ha pasado con la mayoría de campesinado colombiano. Este artículo sustenta y argumenta el porqué las tierras constituyen la base física indispensable de la identidad cultural por proteger y desarrollar en vez de someterla al mercado" (Viafara, 2003).

En el mismo sentido, el alto componente conservacionista de la ley 70 (pues de uno u otro modo este tema está inmerso en todos los capítulos) hace que además de lo anterior existan serias prohibiciones contra la palma aceitera.

Pese a todo lo anterior, en la actualidad se están llevando a cabo negociaciones ${ }^{19}$ con los consejos comunitarios ${ }^{20}$; hecho que hace latente una gran preocupación porque, como ya se dijo, estos territorios pertenecen a las comunidades negras y están blindados por la constitución y la ley.

En el municipio de Guapi ya se tiene un previvero para luego invadir el mismo con palma africana. Claro está que en el pasado ya se había intentado establecer la palma en esta entidad territorial, pero no funcionó, ahora parece ser que sí va tener éxito, en cuanto que, a pesar de todas sus artimañas, no han podido convencer a la gente. De esta forma se expresa lo siguiente:

"En Guapi, el fantasma de la palma aceitera ronda y amenaza los territorios. Se menciona que un Consejo Comunitario ha entregado en concesión a la empresa palmera Salamanca su territorio por casi una vida, 60 años. Sin embargo, nos da esperanza saber que de los 18 Consejos Comunitarios sólo éste cayó ante las falsas ilusiones de quienes promueven el negocio de la palma. Los otros Consejos siguen sin aceptar este megaproyecto y se fortalecen en torno a sus Planes de Etnodesarrollo" (Roa, 2008).

De igual forma se calcula que también van a talar gran parte de bosque natural ${ }^{21}$, aunque los que están a favor de estas plantaciones argumenten lo contrario, sabiendo que la misma guía ambiental para el subsector de la agroindustria africana -de forma maquillada- lo contempla al decir que uno de los tantos impactos ambientales se da por "erradicación y renovación de plantaciones". En este punto es importante recalcar que las plantaciones no son bosques.

No sobra dejar claro que los derechos territoriales (adquiridos por centenares de años y reconocidos por el Estado apenas hace un poco más de tres lustros) de las comunidades rurales del Litoral pacífico han sido violados y vulnerados, con el agravante de que no se están realizando acciones que a partir de la ley 70 de 1993 se hacen evidentes, como lo es una reforma constitucional para que, al igual que los resguardos indígenas, los territorios colectivos de las comunidades negras sean 
denominados entidades territoriales y de esta forma puedan percibir ingresos directos de la nación, hecho que, sumado a otras iniciativas de carácter económico y social (como la conformación de asociaciones locales "cooperativas"), contribuiría enormemente al anhelado "etnodesarrollo" que tanto necesita esta región. El solo hecho de que las comunidades tengan la tierra no lo garantiza todo, por el simple planteamiento que se hace desde la economía, el cual tiene como premisa fundamental "que la base para producir es la tierra, el capital y el trabajo".

El futuro que le espera al sector rural del Chocó Biogeográfico es bastante incierto. Sin embargo, existe la esperanza de un mejor amanecer, amanecer que expresado en palabras de un grupo musical de la región ("cantaores" de música folclórica "currulao" y "chirimía") ritma diciendo: "no pierdan la fe, no pierdan la fe, que se puede vivir en el campo también".

\section{CONCLUSIONES Y RECOMENDACIONES}

De manera general sobre de palma africana:

"Se encuentra que esta plantación no permite mejorar las condiciones de vida de los campesinos, la situación ambiental y salir de la pobreza; por el contrario únicamente sirve para enriquecer a los empresarios, en detrimento de los más pobres y de la degradación ambiental, debido a que los impactos ambientales y sociales de la reina de las oleaginosas provoca se incrementa cuando el área plantada aumenta" (Ramírez, 2003).

- La agroindustria de la palma de aceite (promovida por el auge de los agrocombustibles) ha violado la Constitución Política y la ley 70 de 1993, las cuales ampara a los territorios colectivos de las comunidades afrocolombianas, blindándolos contra este tipo de megaproyectos.

- Los impactos ambientales y sociales que ha causado la palma africana en el pacífico pueden ser iguales o peores a los que generan los cultivos de uso ilícito.

- En los municipios del pacífico en los que se ha implementado la palma aceitera (junto a la actividad maderera) se ha causado tala de la selva, hecho que ha afectado la biodiversidad; además, ahora esta diversidad biológica se encuentra frente a un nuevo peligro como lo es la modificación genética de la palma africana.

- El pacífico colombiano presenta un futuro incierto por las políticas mundiales y nacionales que propician monocultivos de plantaciones como la palma africana.

- Se hace necesario repensar el modelo bajo el cual se implanta la palma africana, aunque por todo el negocio que gira alrededor de ésta es muy difícil augurar cambios en el mismo.

\section{BIBLIOGRAFÍA}

- Andrade Germán. Pacífico biodiverso. En: Ecológica. Bogotá. Año IV N¹5-16 (octubre 1993); p. 5.

- Arias Leyva, Andrés F. Estrategia de desarrollo de biocombustibles: implicaciones para el sector agropecuario. En: Expo Universidad. Medellín. 2007; p. $13-14$. 
- Asamblea Nacional Constituyente. Constitución política de 1991. [21] Ley 70 de 1993. Por la cual se desarrolla el artículo transitorio 55 de la Constitución Política.

- Bermúdez Rico, Rosa. Megaproyectos de infraestructura y agrocombustibles en el pacífico colombiano. En: Censat Agua Viva. Agrocombustibles: Ilenando tanques, vaciando territorios. Colombia. 2008, p.174.

- Carrare, Ricardo. Palma aceitera: la expansión de otro monocultivo destructivo. En: Movimiento mundial por los bosques tropicales: el amargo fruto de la palma aceitera. Montevideo, Uruguay: Novib - UITA, 2001, p. 15.

- Copete, Víctor. (Memorias) Foro regional IIAP el Chocó biogeográfico, 12 años después de la ley 70 de 1993. Quibdó, Chocó. 1, 2 y 3 de junio de 2005.

- Díaz, Servio T. Proyecto biopacífico. En: Ecológica. Bogotá. Año IV N¹5-16 (octubre 1993); p. 31.

- Diócesis de Quibdó. El cultivo de la palma africana en el Chocó. Quibdó: SUIPPCOL, 2004, p. 109 - 152.

- Escobar, Arturo y Pedrosa, Álvaro. Pacífico: biodiversidad o desarrollo. Bogotá: Ecofondo - Cerec, 1996, p. 109 - 115.

- FEDEPALMA. Guía ambiental para el subsector de la agroindustria de la palma de aceite. Bogotá: 2002, p. 57 - 58.

- Ferrand, Maurice. Informe sobre posibilidades de las oleaginosas en Colombia. En: Escobar, Arturo y Pedrosa, Álvaro. Pacífico: biodiversidad o desarrollo. Bogotá: Ecofondo - Cerec, 1996, p. 112.

- Gentry, Alwyn. Sabemos más de la luna que del Chocó. En: Ecológica. Bogotá. Año IV N¹5-16 (octubre 1993); p. 59.

- Guhl Nanneti, Ernesto. CATEDRA AMBIENTAL: PENSAMIENTO Y POLÍTICA AMBIENTAL. (2007: Pereira). Memorias del II año de cátedra ambiental. Universidad Tecnológica de Pereira.

- Ley 99 de 1993. Por la cual se crea el ministerio del medio ambiente y se reordena el sector público encargado de la gestión ambiental en Colombia.

- Movimiento mundial por los bosques tropicales: el amargo fruto de la palma aceitera. Montevideo, Uruguay: Novib - UITA, 2001, p. 91.

- Incoder, 2005. Informe de la comisión de verificación realizada entre el 25 de octubre y el 1 de noviembre de 2004, citado por Bermúdez Rico, Rosa. Megaproyectos de infraestructura y agrocombustibles en el pacífico colombiano. En: Censat Agua Viva. Agrocombustibles: Ilenando tanques, vaciando territorios. Colombia. 2008, p. 174- 175.

- Pérez - Rincón, Mario A. Los agrocombustibles: ¿sólo canto de sirenas? En: Censat Agua Viva. Agrocombustibles: Ilenando tanques, vaciando territorios. Colombia. 2008, p. 88.

- Ramírez C, Gloria L. Palma africana: oportunidad o amenaza para el ambiente y para el país. En: Gestión y ambiente. Manizales. Vol. 6 No 2 (diciembre de 2003); p. 137.

- Restrepo, Eduardo. Hacia una etnografía del cultivo de la palma africana en Tumaco. En: Universitas humanística. Bogotá. Año XXXI № 58 (abril 22 de 2004); p.73- 87.

- Roa A, Tatiana. Campaña en resistencia a los agrocombustibles: Llenando tanques, vaciando territorios. Bogotá: Censat Agua Viva. 10 p.

- Sokoudjou, Herve. El caso de Camerún: las plantaciones de palma aceitera. En: Movimiento mundial por los bosques tropicales: el amargo fruto de la palma aceitera. Montevideo, Uruguay: Novib - UITA, 2001, p. 23 - 34.

- Vargas C, Mónica. La deuda ecológica de los agrocombustibles. En: Censat Agua Viva. Agrocombustibles: llenando tanques, vaciando territorios. Colombia. 2008, p. 69. 
- Vargas G, Celso A. Energía y medioambiente. En: Gestión y ambiente. Manizales. Vol. 10 No 3 (diciembre de 2007); p. 79.

- Vélez, Irene y Vélez, Hildebrando. Los espejismos de los agrocombustibles. En: Censat Agua Viva. Agrocombustibles: llenando tanques, vaciando territorios. Colombia. 2008, p. 27- 44.

- Viafara Valverde, Elder J. Aspectos políticos y sociales de la ley 70/1993 en el municipio de Guapi, Cauca. Popayán, 2003, 100 p. trabajo de grado (Politólogo). Universidad del Cauca. Facultad De Derecho, Ciencias Políticas Y Sociales. Área Ciencia Política.

\section{NOTAS}

1. En general todos los ecosistemas del pacífico se consideran que son frágiles, resaltando las selvas inundables, como lo son los guandales (predomina el guandal), natales (predomina el nato), sajales (predomina el sajo), cuangariales (predomina el cuángare), catival (predomina el cativo). Debido a la pobreza de nutrientes de los suelos del pacífico su biodiversidad se mantiene gracias al reciclaje de nutrientes.

2. Este término es utilitarista, desafortunadamente la riqueza natural sólo es vista como un activo para el ser humano, sin ni siquiera considerar el valor en sí que tiene cada ser, sea viviente o no.

3. En la actualidad y desde ya hace más de dos décadas a este fenómeno de deforestación se le ha sumado la causada por la introducción de la Palma Africana, hecho que agravara los cálculos.

4. Víctor Copete en un Foro realizo en Quibdó en el año 2005 plantea que al Instituto de Investigaciones Ambientales del Pacifico sólo se le asignan 2000 millones de pesos al año, de los cuales 1500 se designaban a pagos de funcionamiento y gastos generales, y 500 millones a inversiones.

5. El Norteamericano Alwyn Gentry fue uno de los primeros biólogos que alertó a la comunidad científica sobre la altísima biodiversidad del Choco Biogeográfico.

6. Como ejemplo tenemos Malasia, Indonesia, Papúa Nueva Guinea, el mismo Colombia, entre otros.

7. Irene Vélez y Hildebrando Vélez plantean que la cantidad de trabajadores por hectárea es supremamente baja en la agroindustria de la palma. Así, por ejemplo, la agroindustria de la caña y la palma genera solamente 10 empleos por cada 100 hectáreas mientras la agroindustria de la soya dos por cada cien.

8. La ley 99 de 1993 establece que se entiende por desarrollo sostenible el que conduzca al crecimiento económico, a la elevación de la calidad de la vida y al bienestar social, sin agotar la base de recursos naturales renovables en que se sustenta, ni deteriorar el medio ambiente o el derecho de las generaciones futuras a utilizarlo para la satisfacción de sus propias necesidades.

9. Región comprendida por algunos municipios de los departamentos del Cauca, Nariño y Valle, además de la totalidad del departamento del Chocó. Cabe anotar que municipios que ahora pertenecen a los departamentos de Antioquia y Risaralda 
antes pertenecían al departamento del Chocó, hecho que confirma las condiciones bioclimáticas y la composición poblacional.

10. Entre el 10 y el $11 \%$ de esta producción corresponde a la zona occidental (Tumaco, Guapi y B/tura), aunque realmente la implementación de esta plantación en esta primera fase sólo prosperó en Tumaco.

11. Esta modalidad es una estrategia de asegurar la oferta de fruto palma en las tierras donde se oponen a ser vendidas, y es aplicada en todos los países donde se ha establecido esta palma, esta modalidad es conocida como "Fincas de núcleos y pequeños propietarios" y fue introducida por el Banco Mundial a principios de los años 80.

12. La Guía ambiental para el subsector de la agroindustria de la palma de aceite enumera algunos de los impactos ambientales de la palma, mencionando sólo los principales obtenemos que son ocasionados por: adecuación de tierras, erosión, compactación de suelos, manejo de riego y drenajes, manejo de recursos hídricos, manejo de previveros y viveros, manejo de productos químicos, manejo de abonos y fertilizantes, manejo de plagas y enfermedades, erradicación y renovación de plantaciones, construcción y adecuación de vías, manejo de subproductos sólidos, manejo de aguas residuales, manejo de emisiones atmosféricas, manejo de residuos sólidos, manejo de residuos peligrosos y tóxicos, asuntos sociales.

13. Incoder, 2005. Informe da la comisión de verificación realizada entre el 25 de octubre y el 1 de noviembre de 2004.

14. Territorios en los que estas comunidades han vivido por centenares de años.

15. El problema de estas fuentes alternativas de energía es que resultan siendo un nuevo nicho económico para las grandes corporaciones trasnacionales.

16. En 2005 ocupaba el sexto lugar en área sembrada en el país después del maíz, café, arroz, cana y plátano.

17. La ley 99 de 1993 en su artículo 5 punto 40 reza que hay que fijar con carácter prioritario, las políticas ambientales para la Amazonía colombiana y el Chocó Biogeográfico, de acuerdo con el interés nacional de preservar estos ecosistemas.

18. Según art. 6 ley 70 de 1993.

19. El caso del pacífico caucano (Guapi y Timbiquí) y Nariñense (Charco y Izcuandé). Se calcula implantar 13.000 hectáreas de palma.

20. En los territorios colectivos los consejos comunitarios son la máxima autoridad, de esta forma este órgano aprueba o reprueba cualquier actividad productiva o interviene en algún problema que se presente dentro de estos territorios.

21. De acuerdo con las proyecciones de palma africana de se pretenden implantar. Inicialmente son 700 hectáreas 